\title{
Cultivo in vitro del tomate de árbol (Cyphomandra betacea (Cav.) Sendt. (Fenotipo naranja) proveniente de Costa Rica
}

\author{
In vitro culture of Tamarillo (Cyphomandra betacea \\ (Cav.) Sendt. (Orange Phenotype) from Costa Rica.
}

Randall Chacón-Cerdas'

Dora Flores-Mora'

Luis Alvarado-Marchena'

Alexander Schmidt-Durán'

Carlos Alvarado-Ulloa'

Fecha de recepción: 23 de julio del 2013 Fecha de aprobación: 07 de octubre del 2013

\begin{abstract}
Chacón-Cerdas, R; Flores-Mora, D; Alvarado-Marchena, L; Schmidt-Durán, A; Alvarado-Ulloa, C. Cultivo in vitro del tomate de árbol (Cyphomandra betacea

(Cav.) Sendt. (Fenotipo naranja) proveniente de Costa Rica. Tecnología en Marcha.VI Encuentro de Investigación y Extensión. Pág
\end{abstract}




\section{Palabras clave}

Cyphomandra betacea; establecimiento in vitro; multiplicación in vitro; enraizamiento in vitro.

\section{Resumen}

El tomate de árbol (Cyphomandra betacea) es un frutal de importancia comercial en países como Bolivia, Colombia, Ecuador y Perú, donde se consume como fruta fresca y procesada. Tradicionalmente, es propagado por semillas y estacas, y enfrenta problemas de heterogeneidad y calidad de material de siembra.

En esta investigación se desarrolló un protocolo para la micropropagación in vitro del tomate de árbol criollo del fenotipo naranja, proveniente de Costa Rica, el cual presenta potencial para la diversificación agrícola y la agroindustria. Se evaluaron dos tratamientos de desinfección in vitro con variaciones en la concentración del $\mathrm{Ca}(\mathrm{ClO})$, 2,5\% y 5,0\% (i.a $75 \%)$, tres tratamientos para la multiplicación in vitro del material con diferentes reguladores de crecimiento y concentración de sales MS (1962), y seis tratamientos para el enraizamiento in vitro con diversos reguladores de crecimiento y gelificantes.

Se determinó que la desinfección con 2,5\% de $\mathrm{Ca}(\mathrm{ClO})_{2}$ fue la mejor para el establecimiento in vitro; el mejor medio de cultivo para la micropropagación del material fue el MI, compuesto por sales MS(1962) al 100\%, sacarosa al 3\%, phytage|® I,8g/L, 0,5mg/L de $A_{3}, 0,25 \mathrm{mg} / \mathrm{L}$ de BAP y 2,0 $\mathrm{mg} / \mathrm{L}$ de $\mathrm{PaCa}$, el cual presentó el mejor balance entre el número promedio de brotación/explante y el número promedio de entrenudos/explante, sin formación excesiva de callo, mientras que el medio de cultivo E5, constituido por sales MS(1962) al $100 \%$, agar $6,0 \mathrm{~g} / \mathrm{L}$ y sacarosa al $3 \%$, sin reguladores del crecimiento y el medio de cultivo E6, que incluía las sales MS(1962) al 100\%, agar 8,0g/L y sacarosa al $3 \%$, sin reguladores del crecimiento, mostraron el periodo más corto para la formación de raíces, el mayor número promedio de raíces y la mayor longitud promedio de raíz y tallo.

\section{Key words}

Cyphomandra betacea; in vitro establishment; in vitro multiplication; in vitro rooting.

\section{Abstract}

Tamarillo or tree tomato (Cyphomandra betacea), is a fruit plant of commercial importance in countries such as Bolivia, Colombia, Ecuador, and Peru, where it is consumed as a fresh or processed fruit. Traditionally, it is grown through seeds or plant cuttings, leading to problems regarding heterogeneity and quality of the planting material. In this research, an in vitro micropropagation protocol was developed for a domestic tree tomato, from Costa Rica, and of the orange phenotype; which has considerable potential for its use in agroindustry and in agricultural diversification. Two different in vitro disinfection treatments were evaluated, with variations of 2,5\% and 5,0\% (a.i 75\%) for $\mathrm{Ca}(\mathrm{ClO})_{2}$. Three in vitro multiplication treatments of the plant material with different growth regulators and MS salts (1962) concentrations, as well as six in vitro rooting treatments with various growth regulators and gelling agents were also tested. Through the study, it was established that the disinfection with 2,5\% of $\mathrm{Ca}(\mathrm{ClO})_{2}$ was the best for in vitro establishment. Additionally, the research evidenced that the optimal micropropagation growth medium consisted of $\mathrm{MI}$, comprised of 100\% MS salts (1962), 3\% sucrose, I,8g/L of Phytage| $囚, 0,5 \mathrm{mg} / \mathrm{L}$ de $\mathrm{AG}_{3}, 0,25 \mathrm{mg} / \mathrm{L}$ of $\mathrm{BAP}$ and $2,0 \mathrm{mg} / \mathrm{L}$ of $\mathrm{PaCa}$; which presented the most adequate balance between the average number of budding/cutting and the average number of internode/cutting, without the excessive formation of callus. Meanwhile, the M5 growth medium, consisting of 100\% MS salts (1962), 6,0g/L of agar, $3 \%$ sucrose and without any growth regulators, as well as the E6 growth medium, including 100\% MS salts (1962), 8,0g/L of agar, 3\% sucrose, and without growth regulators, both required a shorter period for root formation, a higher average number of roots, and in average longer stems and roots. 


\section{Introducción}

El tomate de árbol (Cyphomandra betacea), perteneciente a la familia Solanaceae, es una planta propagada tradicionalmente por semillas y estacas, en países como Bolivia, Colombia, Ecuador y Perú (Espinosa, Trillos, Hoyos, Afanador y Correa, 2005); sin embargo, a pesar de que estos sistemas de multiplicación han suplido las necesidades de material, presentan limitaciones en relación con la disponibilidad de variedades con alta productividad, la baja calidad de los frutos, la heterogeneidad del material vegetal, y la proliferación de microorganismos patógenos existentes en la planta (Lobo, 200 I).

Una alternativa a la propagación convencional y sus limitantes, es la utilización de procedimientos basados en el cultivo in vitro, que permiten multiplicar de forma rápida, económica y rentable, material élite en cualquier época del año. Aspectos como la calidad del explante utilizado, su procedencia, el protocolo de desinfección, la asepsia, el medio de cultivo empleado en cada una de las diferentes etapas y las condiciones físicas de incubación son fundamentales para el desarrollo exitoso de esta técnica (Calva y Pérez, 2005). El conjunto de estos factores dentro del sistema in vitro permiten la reproducción de plantas completas a partir del material seleccionado e introducido, logrando mantener un material axénico, viable y vigoroso para su adecuada manipulación (Correia, Lopes y Canhoto, 20 I I).

En Costa Rica, los agricultores se han dedicado, principalmente, a la producción de cultivos tradicionales como la piña, el banano y el café, dependiendo considerablemente de estos cultivos. Sin embargo, existen otros frutales, como el tomate de árbol, con potencial para la diversificación agrícola y la agroindustria. Por esta razón, el objetivo de este trabajo fue el establecimiento de la micropropagación in vitro del tomate de árbol criollo del fenotipo naranja, con el fin de disponer de material de alta calidad.

\section{Materiales y métodos}

Los ensayos se realizaron en el Centro de Investigación en Biotecnología del Instituto Tecnológico de Costa Rica.

\section{Selección y colecta de material vegetal}

Se colectaron estacas de tomate de árbol en la zona agrícola de Pacayas en Cartago en las coor-

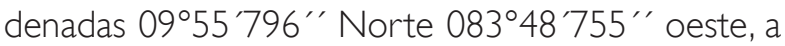
una altitud de 1907 msnm. Se seleccionaron ramas vigorosas de árboles del fenotipo color naranja y se confeccionaron estacas con una longitud aproximada de $40-45 \mathrm{~cm}$ de largo por 1,4 cm de ancho, las cuales presentaron, en promedio, cinco entrenudos. Se preparó un sustrato a base de suelo y granza de arroz en una proporción de 3:I y se desinfectó con un producto a base de Carboxin al 20\% de ingrediente activo (i.a.), y Thiram (20\% i.a) a razón de $0,17 \mathrm{~g} / \mathrm{kg}$ de sustrato.

Las estacas se sembraron enterrando al menos tres nudos en bolsas de polietileno de un volumen de $2 \mathrm{~kg}$ con sustrato y se ubicaron en un invernadero para la inducción de su brotación. Al corte apical expuesto se le aplicó una pasta del desinfectante para evitar el ingreso de patógenos al interior del material.

\section{Introducción in vitro por miniestacas}

Se seccionaron brotes de las estacas localizadas en el invernadero y se cortaron explantes de 2,0-4,0 $\mathrm{cm}$ de longitud con uno o dos nudos que presentaban yemas axilares visibles.

Los explantes se lavaron con agua y jabón antibacterial. Posteriormente, se colocaron en un sonicador con $400 \mathrm{ml}$ de agua destilada, $5 \mathrm{ml}$ de jabón antibacterial y un biodesinfectante extraído a partir de semillas de toronja (Kilo|ß $5 \mathrm{ml} / \mathrm{L}$ ), se expusieron a dos ciclos de 3,5 minutos cada uno, y se cambió por una solución fresca en cada ciclo. Luego, se sometieron a una inmersión en etanol de 95\% por un minuto y se colocaron en una solución compuesta por $5 \mathrm{~g} / \mathrm{L}$ de benomilo (50,0\% i.a.), $5 \mathrm{~g} / \mathrm{L}$ de sulfato de gentamicina $(2,0 \%$ i.a.) con clorhidrato de oxitetraciclina (6,0\% i.a.) y 5,0 g/L de dimetiltiocarbamato (76,0\% i.a.), por un período de 70 minutos. Los primeros 20 minutos, se llevaron a cabo en una cámara de vacío; y los 50 minutos restantes trascurrieron en un agitador orbital.

Posteriormente se trasladaron a una cámara de flujo laminar, donde se realizaron tres lavados con agua destilada estéril hasta eliminar los excesos de agroquímicos en el tejido. Por último, los explantes se dividieron en dos tratamientos. Ambos se 
sumergieron por cinco minutos en una solución de hipoclorito de calcio $\left(\mathrm{Ca}(\mathrm{ClO})_{2}\right)$, el primer grupo al $5,0 \%$ (i.a al $75 \%$ ) y el otro al 2,5\% (i.a al $75 \%$ ) y luego se realizaron tres lavados con agua destilada estéril.

Los explantes se inocularon en un medio de cultivo líquido Murashige y Skoog (MS) (1962) completo, suplementado con $3 \%$ de sacarosa y $0,5 \mathrm{mg} / \mathrm{L}$ de ácido giberélico $\left(\mathrm{AG}_{3}\right)$, utilizando el sistema de puente con papel filtro en tubo de ensayo con 10 $\mathrm{ml}$ de medio cada tubo. Antes de ser inoculados, se les eliminó a los explantes el tejido dañado. Se realizaron tres repeticiones por tratamiento con 20 microestacas por repetición y se evaluó el porcentaje de sobrevivencia-asepsia y la brotación, luego de cuatro semanas de observación.

\section{Micropropagación}

Para la micropropagación se establecieron tres medios de cultivo. Se determinó estadísticamente el efecto sobre la cantidad de brotes por explante y la cantidad de entrenudos por brote luego de un periodo de crecimiento de seis semanas. Además, se evaluó la sobrevivencia y el porcentaje de enraizamiento total por tratamiento. La composición de los medios de cultivo se detalla en el cuadro 1 .

Los explantes se inocularon individualmente en frascos de vidrio con $20 \mathrm{ml}$ de medio de cultivo. Las microestacas se incubaron a $26{ }^{\circ} \mathrm{C}$ y un fotoperíodo de 16 horas luz. Se realizaron dos repeticiones de 25 explantes por tratamiento.

\section{Enraizamiento in vitro}

Se seleccionaron brotes de 3-4 cm de longitud del mejor tratamiento de multiplicación y se inocularon en seis tratamientos, con diferentes medios de cultivo, en medio semisólido. La composición de los medios de cultivo se detalla en el cuadro 2 .

Los explantes se inocularon individualmente en frascos de vidrio con $20 \mathrm{ml}$ de medio de cultivo. Se evaluaron 30 explantes por tratamiento. Se analizaron los siguientes parámetros: días promedio de

Cuadro I.Tratamientos para la micropropagación del tomate de árbol fenotipo naranja

\begin{tabular}{|c|c|c|c|c|c|c|c|c|c|c|}
\hline Tratamiento & $\mathrm{pH}$ & Sacarosa & $\begin{array}{c}\text { \% Sales } \\
\text { MS }\end{array}$ & $\begin{array}{c}\text { Gelificante } \\
(\mathrm{g} / \mathrm{L})\end{array}$ & $\begin{array}{c}\mathrm{AG}_{3} \\
(\mathrm{mg} / \mathrm{L})\end{array}$ & $\begin{array}{c}\text { BAP } \\
(\mathrm{mg} / \mathrm{L})\end{array}$ & $\begin{array}{l}\mathrm{PaCa} \\
(\mathrm{mg} / \mathrm{L})\end{array}$ & $\begin{array}{c}\text { Zeatina } \\
(\mathrm{mg} / \mathrm{L})\end{array}$ & $\begin{array}{c}\text { Tiamina } \\
(\mathrm{mg} / \mathrm{L})\end{array}$ & $\begin{array}{c}\text { Glutamina } \\
(\mathrm{mg} / \mathrm{L})\end{array}$ \\
\hline MI & \multirow[b]{3}{*}{5,7} & \multirow[b]{3}{*}{$30 \mathrm{~g} / \mathrm{L}$} & \multirow{2}{*}{100} & \multirow{2}{*}{$\begin{array}{c}\text { Phytage| } \circledast 8 \\
(1,8 g / L)\end{array}$} & 0,50 & 0,25 & 2,00 & --- & --- & --- \\
\hline M2 & & & & & 0,50 & 0,50 & 2,00 & --- & --- & -- \\
\hline M3* & & & 50 & $\begin{array}{c}\text { Difco } \\
\text { Bacto Agar } \\
(1 \mathrm{I}, 0 \mathrm{~g} / \mathrm{L})\end{array}$ & --- & --- & --- & 2,00 & 0,90 & 5,00 \\
\hline
\end{tabular}

* Medio tomado de Contreras y Almeida (2005).

Cuadro 2.Tratamientos para el enraizamiento in vitro del tomate de árbol fenotipo naranja

\begin{tabular}{|c|c|c|c|c|c|c|c|}
\hline Tratamiento & $\begin{array}{c}\text { \% Sales } \\
\text { MS }\end{array}$ & Gelificante (g/L) & $\begin{array}{c}\mathrm{AG}_{3} \\
(\mathrm{mg} / \mathrm{L})\end{array}$ & $\begin{array}{c}\text { AlA } \\
(\mathrm{mg} / \mathrm{L})\end{array}$ & $\begin{array}{c}\text { AlB } \\
(\mathrm{mg} / \mathrm{L})\end{array}$ & \% Sacarosa & $\mathrm{pH}$ \\
\hline El & \multirow{6}{*}{100} & \multirow{4}{*}{ Phytage| $®(1,8)$} & - & - & - & \multirow{4}{*}{3,00} & \multirow{6}{*}{5,70} \\
\hline E2 & & & 0,50 & - & - & & \\
\hline E3 & & & - & 0,50 & - & & \\
\hline E4 & & & - & - & 0,50 & & \\
\hline *E5 & & Agar $(6,0)$ & - & - & - & \multirow{2}{*}{2,40} & \\
\hline E6 & & Agar $(8,0)$ & - & - & - & & \\
\hline
\end{tabular}

* Medio de cultivo tomado de Correia et al. (20 I I) 
enraizamiento, número promedio de raíces, longitud promedio de raíces principales obtenidas y longitud promedio del tallo de la vitroplanta. Los ensayos se incubaron a $26^{\circ} \mathrm{C}$ y 16 horas luz durante seis semanas.

\section{Análisis estadístico}

Se realizó un análisis de varianza mediante el Modelo Lineal General (MLG), estadístico $F$ y se utilizó la prueba de Fisher con un 95\% de confianza para discriminar entre los tratamientos, lo anterior luego de corroborar los supuestos estadísticos de homocedasticidad, identificación de la distribución individual de datos y la aleatoriedad mediante el software estadístico Minitab® I6 (Minitab, 20 I0).

\section{Resultados}

Introducción in vitro por miniestacas

A partir de la prueba de desinfección de miniestacas para el establecimiento y brotación in vitro, se determinó que el tratamiento con $\mathrm{Ca}(\mathrm{ClO})_{2}$ al 5,0\% presentó menor sobrevivencia debido a una mayor oxidación de los explantes en comparación con el tratamiento de $\mathrm{Ca}(\mathrm{ClO})_{2}$ al 2,5\% (cuadro 3).

La menor concentración del desinfectante mostró un mayor porcentaje de sobrevivencia de los explantes asépticos y brotación del material. En la figura IA se presenta la brotación de las miniestacas introducidas in vitro.

\section{Micropropagación}

En relación con las variables número promedio de brotes/explante y número promedio de entrenudos/ brote, únicamente se presentó diferencia significativa para la primera variable mencionada. El tratamiento M2 presentó el mayor número promedio de brotes/ explante. Las plantas de los tratamientos $\mathrm{MI}$ y M2 mostraron una apariencia vigorosa con respecto al tratamiento M3, el cual presentó brotes rojizos. Hubo formación de callo en todos los tratamientos (figura IB). En el cuadro 4 se muestra la comparación estadística de los tratamientos.

Cuadro 3. Sobrevivencia y brotación in vitro de miniestacas de vitroplantas de tomate de árbol fenotipo naranja.

\begin{tabular}{|c|c|c|}
\hline Tratamiento & $\begin{array}{c}\text { \% Sobrevivencia } \\
(\mathrm{p}=0,049)\end{array}$ & $\begin{array}{c}\text { \% Brotación } \\
(\mathrm{p}=0,77 \mathrm{I})\end{array}$ \\
\hline $\mathrm{Ca}(\mathrm{ClO})_{2}(2,5 \%)$ & $35,13 \pm 27,86 \mathrm{a}$ & $79,63 \pm 22,43 \mathrm{a}$ \\
\hline $\mathrm{Ca}(\mathrm{ClO})_{2}(5,0 \%)$ & $6,57 \pm 0,23 \mathrm{~b}$ & $69,23 \pm 53,29 \mathrm{a}$ \\
\hline
\end{tabular}

Análisis de varianza GLM, prueba Fisher $\alpha=0,05$.

Letras diferentes indican diferencia estadística significativa entre los tratamientos.

Cuadro 4. Número promedio de brotes/explante y número promedio de entrenudos/brote para los tratamientos de multiplicación in vitro

\begin{tabular}{|c|c|c|}
\hline \multirow{2}{*}{ Tratamiento } & \multicolumn{2}{|c|}{ Promedio de los parámetros } \\
\cline { 2 - 3 } & $\begin{array}{c}\text { Brotes / } \\
\text { Explante }(p=0,000)\end{array}$ & $\begin{array}{c}\text { Entrenudos / } \\
\text { Brote }(p=0,13 \mathrm{I})\end{array}$ \\
\hline M1 & $2,38 \pm 0,49 \mathrm{~b}$ & $4,5 \mathrm{I} \pm 1,68 \mathrm{a}$ \\
\hline M2 & $3,56 \pm 0,42 \mathrm{a}$ & $4,08 \pm 0,92 \mathrm{a}$ \\
\hline M3* & $1,65 \pm 0,53 \mathrm{c}$ & $4,74 \pm 1,54 \mathrm{a}$ \\
\hline
\end{tabular}

Análisis de varianza, prueba Fisher $\alpha=0,05$.

Letras diferentes indican diferencia estadística significativa entre los tratamientos.

* Medio tomado de Contreras y Almeida (2005). 


\section{Enraizamiento in vitro}

El 100\% de enraizamiento se presentó en los tratamientos E3, E5 y E6, mientras que los otros tratamientos mostraron valores menores al 73\%. En relación con el número promedio de días de enraizamiento, los tratamientos E5 (figura IC) y E6 presentaron los ciclos más cortos. En cuanto a la apariencia del material, las plantas de los tratamientos E2, E3 y E4 presentaron callo en la base, de donde se producían las raíces adventicias, no obstante esta callogénesis no se presentó en los tratamientos EI, E5 y E6. En el cuadro 5 se muestra la comparación de los parámetros de enraizamiento evaluados.

\section{Discusión}

Introducción in vitro por miniestacas

El proceso de eliminación de contaminantes microbiológicos mediante desinfectantes químicos y durante la preparación del explante en el establecimiento in vitro, puede inducir la oxidación y muerte de los tejidos, afectando su sobrevivencia (Tabiyeh, Bernard y Shacker, 2006; Van Staden, Fennell y Taylor, 2006). Este efecto se debe al estrés oxidativo y nitrosativo en las células, como consecuencia de la producción de especies de oxígeno reactivo y de nitrógeno reactivo (Turrens, 2003; Valderrama et al., 2007) que entran en contacto con enzimas oxidasas produciendo la muerte celular, esto provocado por condiciones de estrés en el material vegetal (Vatanpour-Azghandi, Villiers, Ghorbani y Tajabadi, 2002; Tang, Harris, Outhavong y Newton, 2004; Pompeu, Gratão, Vitorello y Azevedo, 2008; Cassells y Doyle, 2005; Abdelwahd, Hakam, Labhilili y UduPA, 2008).

El efecto del desinfectante en la disminución de la sobrevivencia está relacionado con la concentración del ingrediente activo. En un estudio realizado por López et al. (20 I I), donde se evaluaron diferentes dosis de $\mathrm{Ca}(\mathrm{ClO})_{2}$ en hojas de café, se demostró que la sobrevivencia de los explantes disminuye con el incremento de la concentración del desinfectante, encontrándose valores de dosis letal media $\left(L_{50}\right)$ de $2,8 \%$ en genotipos sensibles, y $L_{50}$ de $36,5 \%$ en genotipos resistentes, evidenciando la relación genotipo-dosis en la sobrevivencia.

En este estudio se corroboró el efecto significativo de la concentración del $\mathrm{Ca}(\mathrm{ClO})$, sobre la sobrevivencia de un único genotipo de tomate de árbol, donde la dosis de 2,5\% produjo una sobrevivencia significativamente mayor comparada con la dosis de 5,0\%. La sobrevivencia obtenida con la concentración de 2,5\% (35,13\%) fue similar a la obtenida en otras investigaciones sobre el establecimiento in vitro de este cultivo a partir del mismo tipo de explantes (segmentos nodales), Correia, Lopes y Canhoto (20/2) obtuvieron una sobrevivencia de

Cuadro 5. Promedio de días de enraizamiento, número promedio de raíces, longitud promedio de raíces y longitud promedio de tallo para las vitroplantas enraizadas in vitro a 60 días.

\begin{tabular}{|c|c|c|c|c|c|c|}
\hline \multirow[b]{2}{*}{ Tratamiento } & \multirow{2}{*}{$\begin{array}{c}\% \\
\text { Sobrevivencia }\end{array}$} & \multirow{2}{*}{$\begin{array}{c}\% \\
\text { Enraizamiento }\end{array}$} & \multicolumn{4}{|c|}{ Promedios de los parámetros } \\
\hline & & & $\begin{array}{c}\text { Días de } \\
\text { enraizamiento } \\
(p=0,000)\end{array}$ & $\begin{array}{l}\text { Número } \\
\text { de Raíces } \\
(p=0,041)\end{array}$ & $\begin{array}{l}\text { Longitud Raíces } \\
(\mathrm{cm})(p=0,000)\end{array}$ & $\begin{array}{l}\text { Longitud de Tallo } \\
(\mathrm{cm})(p=0,00 \mathrm{I})\end{array}$ \\
\hline El & 97,00 & 72,00 & $24,67 \pm 15,87 \quad a$ & $2,57 \pm 1,47 \quad b$ & $6,13 \pm 2,54 \quad b$ & $5,63 \pm 2,30 \quad b c d$ \\
\hline E2 & 100,00 & 60,00 & $24,94 \pm 14,85 \quad a$ & $2,28 \pm 1,43 \quad b$ & $8,89 \pm 2,83 \quad a$ & $6,32 \pm 2,29 \quad a b c$ \\
\hline E3 & 90,00 & 100,00 & $22,23 \pm 14,40 \quad a$ & $2,85 \pm 1,40 \quad b$ & $5,95 \pm 2,88 \quad b$ & $5,48 \pm 2,36 \mathrm{~cd}$ \\
\hline E4 & 100,00 & 73,00 & $25,77 \pm 10,26 \quad a$ & $3,23 \pm 1,49 a b$ & $6,35 \pm 3,05 \quad b$ & $4,99 \pm 2,35$ \\
\hline E5* & 100,00 & 100,00 & $12,03 \pm 3,38$ & $3,72 \pm 1,47$ a & $9,77 \pm 3,23 \quad a$ & $6,77 \pm 2,36 \quad a b$ \\
\hline E6 & 100,00 & 100,00 & $13,43 \pm 3,96$ & $3,05 \pm 1,47 a b$ & $10,20 \pm 3,34 \quad a$ & $7,55 \pm 2,33$ \\
\hline
\end{tabular}

Análisis de varianza, prueba Fisher $\alpha=0,05$.

Letras diferentes indican diferencia estadística significativa entre los tratamientos.

* Medio de cultivo tomado de Correia et al. (201 I) 

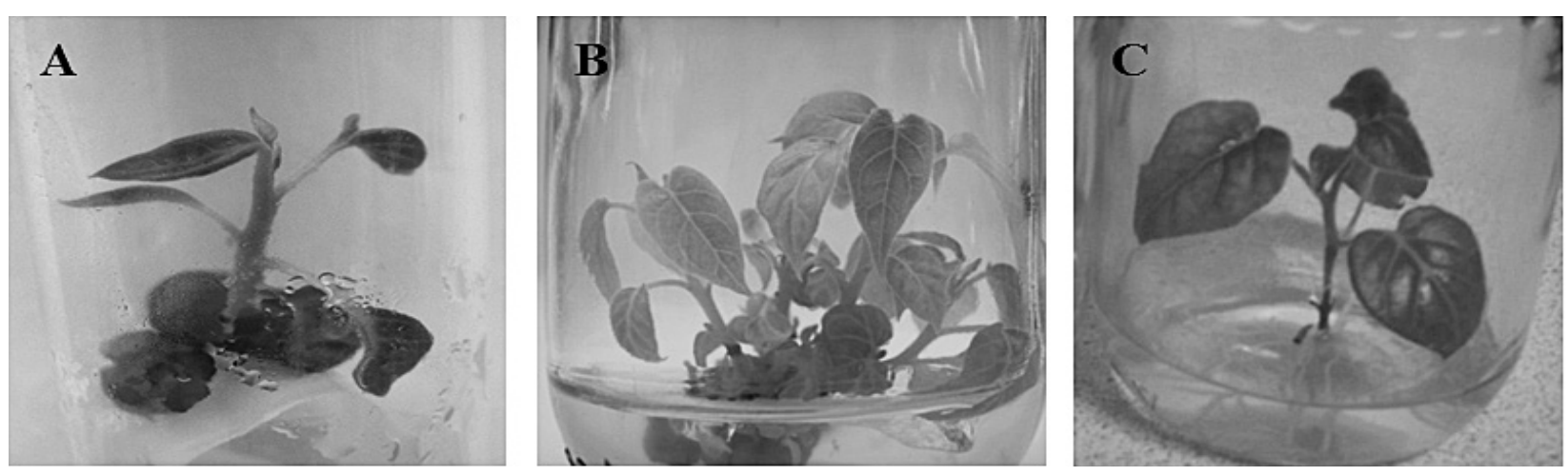

Figura I. Cultivo in vitro de miniestacas de tomate de árbol fenotipo naranja. A. Desinfección con hipoclorito de calcio al 2,5\%. B. Vitroplantas multiplicadas en el tratameinto MI. C.Vitroplantas enraizadas en el tratamiento E5.

un $22 \%$ utilizando $\mathrm{Ca}(\mathrm{ClO})_{2}$ al $5 \%$ en un material de tomate de árbol portugués. Por su parte, Espinosa et al. (2005) obtuvieron porcentajes de sobrevivenciaasepsia que oscilaron entre el 7 y el $37 \%$, utilizando $\mathrm{NaClO}$ al 0,6\% i.a., el cual ha sido reportado como un agente de mayor potencia antimicrobiana, pero con mayor acción oxidante en los tejidos.

Respecto a la brotación, a pesar de que no existió diferencia estadística significativa, se observó que el incremento de la dosis del ingrediente activo de $\mathrm{Ca}(\mathrm{ClO})_{2}$ también disminuyó la brotación de los explantes una vez incubados (Cuadro I). Otros factores abióticos, como la intensidad de la luz en la que se incuban los explantes (Pompeu et al., 2008), la composición y volumen del medio de cultivo, así como las características del recipiente de incubación (Abdelwahd et al., 2008), pueden potenciar la oxidación y muerte de los explantes.

La respuesta del material vegetal también se ve influenciada por la edad del explante, la etapa fisiológica en que se encuentra, la concentración endógena de reguladores de crecimiento, la expresión génica (Preece, 2008), el tamaño y la densidad de inoculación (George, 2008). En este ensayo, al provenir los explantes de estacas de la misma planta y poseer una madurez homogénea, siendo inoculadas e incubadas en las mismas condiciones experimentales, se relaciona la sobrevivencia diferencial al efecto de la desinfección sobre los explantes.

\section{Micropropagación}

Para la micropropagación de la especie en estudio, se ha utilizado una amplia variedad de reguladores de crecimiento, incluidas citoquininas, auxinas y giberelinas. En cuanto a las citoquininas, De Lima et al. (2007), a partir de un material brasileño obtuvieron, luego de 30 días en medios de cultivo MS(1962) con aplicaciones de bencilaminopurina (BAP) en un ámbito de 0,25 a I,00 mg/L, promedios de brotación mayores (4,65-4,85 brotes) a los obtenidos en este ensayo. Además, reportaron para el medio sin reguladores de crecimiento y para la dosis única de 0, $15 \mathrm{mg} / \mathrm{L}$ de BAP, valores similares a la brotación obtenida en este estudio con los medios MI y M2, respectivamente.

Barghchi (1998) reportó, previamente, este ámbito de 0,25 a I,00 mg/L de BAP en medio MS, como el óptimo para generar brotación en explantes de yemas terminales y axilares de tomate de árbol. Canhoto et al. (2005), utilizaron la dosis de 0,5 mg/L de BAP, tanto para el establecimiento como para la brotación de esta especie, a partir de segmentos nodales de plantas adultas. Waweru et al. (20 II) reportaron un promedio de 1,42 brotes al aplicar 40,0 $\mu \mathrm{M} / \mathrm{L}$ de BAP al medio de cultivo MS (1962) en un cultivar de Ruanda.

En otros estudios se ha reportado la combinación de citoquinina/auxina (BA/AIA) como el mejor tratamiento para inducir la proliferación de brotes en tomate de árbol (Espinosa et al., 2005; Contreras y Almeida, 2005).

La aplicación de giberelinas para la multiplicación de tomate de árbol no es frecuente y su uso en este ensayo se realizó para promover la elongación de los entrenudos mediante la activación de los meristemos presentes en estas zonas, de esta forma, 
luego de generarse brotes laterales, las giberelinas favorecen su rápido crecimiento. Su función bioquímica es la activación de proteínas en el catabolismo de polisacáridos, para convertir estos últimos en azúcares disponibles en la generación de energía. En adecuadas combinaciones de giberelinas/citoquininas, se puede inducir la formación de brotes, remplazando el estímulo promovido por la relación auxina/citoquinina (Moshkov, Novikova, Hall y George, 2008).

La bencilaminopurina utilizada en los tratamientos MI y $M 2$ es una citoquinina sintética asociada con la inducción de la brotación lateral en las plantas, sincronizando la activación de yemas laterales. Su efecto en el metabolismo celular está relacionado con los procesos de división celular y la activación enzimática. Su acción tiende a ser dependiente de la luz y se inhibe a altas temperaturas (Van Staden, Zazimalova y George, 2008).

Por otra parte, el pantotenato de calcio (PaCa), es una forma disponible de la vitamina B5, es necesario para la formación de la Coenzima A, la cual participa en la respiración celular y en la síntesis de proteínas, ácidos grasos y carbohidratos (Alberts et al., 2002).

Con base en lo anterior, se explica la brotación obtenida en los explantes de tomate de árbol en los tratamientos MI y M2, en donde la combinación de BAP y $\mathrm{AG}_{3}$ favoreció la obtención de los mayores promedios de brotación. Además, la diferencia significativa de los valores obtenidos en estos tratamientos se debió a la diferencia de concentración de BAP utilizada.

No obstante, la concentración del regulador del crecimiento puede afectar otros procesos ontogénicos en las plantas, especialmente con altas dosis donde el efecto tiende a ser antagónico al desarrollo esperado; por ejemplo, para las citoquininas se ha comprobado que se producen tallos pequeños que no elongan, que pueden volverse hiperhídricos y pueden aparecer deformaciones en las hojas (Van Staden et al., 2008); o bien se redirecciona la organogénesis en procesos de callogénesis o variaciones celulares importantes que pueden radicar en alteraciones genéticas. En un estudio realizado por Canhoto et al., (2005) en tomate de árbol determinaron que la zeatina (citoquinina) influye en la generación de callo embriogénico en explantes nodales y de hoja conforme se aumentó la dosis de 0,5 a $1,0 \mathrm{mg} / \mathrm{L}$.
Lo anteriormente descrito se relaciona con la generación de gran cantidad de callo en el tratamiento M2 con 0,5 mg/L de BAP, en comparación con el tratamiento MI que incluía la mitad de la dosis. Para el parámetro de número promedio de entrenudos/ brote no se encontraron efectos significativos en este proceso de crecimiento y desarrollo.

El tratamiento $\mathrm{M} 3$, utilizado anteriormente por Contreras y Almeida (2005), incluye la aplicación de zeatina como principal regulador de crecimiento, la cual, al igual que el BAP, está relacionada con la división celular y la activación enzimática (Van Staden et al., 2008; Den Boer y Murray, 2000), así como el enriquecimiento del medio con la vitamina tiamina y el aminoácido glutamina, los cuales estimulan en crecimiento.

En su ensayo, Contreras y Almeida (2005) utilizaron explantes de hipocótilo y cotiledones, obteniendo valores promedio de regeneración de yemas de novo de 2,33/hipocótilo y de 10,00/cotiledón, luego de cuatro semanas de incubación, promedios mayores, en ambos casos, a los resultados obtenidos en esta investigación utilizando como explante, brotes individualizados. De esta forma, la baja brotación obtenida se atribuye a variables intrínsecas del material utilizado, principalmente a la posibilidad del uso de diferentes variedades y la edad de las estacas de donde se tomaron los explantes, entre otros factores.

Al comparar los tratamientos $\mathrm{Ml}$ y $\mathrm{M} 2$ con el M3, la disminución de la brotación en este último se atribuye a los reguladores de crecimiento utilizados, a la reducción de las sales al 50\%, y al tipo de gelificante. Diversos estudios han señalado el efecto negativo de la reducción de sales en el crecimiento, debido a la naturaleza esencial de los micro- y macronutrientes para sostener el desarrollo activo, además aplicando diferentes tipos de gelificantes se inducen respuestas heterogéneas sobre los materiales, debido a que aportan diferencialmente trazas de elementos (George, Hall y De Klerk, 2008).

En resumen, el número promedio de entrenudos/ brote no mostró diferencia estadística significativa entre los tres tratamientos, la mayor cantidad la presentó M3, MI y M2 respectivamente. Además entre $\mathrm{Ml}$ y $\mathrm{M} 2$ el mejor tratamiento para la multiplicación del material fue el Mlya que, con la mitad de la citoquinina (BAP), se produjeron vitroplantas 
con brotes vigorosos y menor cantidad de callo, protegiendo la integridad genética del material.

Asimismo, no existe diferencia entre el número promedio de entrenudos/brote entre tratamientos, siendo más alta para MI que para M2. El tratamiento $M 3$ presentó el número promedio de brotes/ explante más bajo y algunos problemas de vigor en los nuevos brotes, relacionados con la nutrición limitada que el medio proporcionó a las vitroplantas.

\section{Enraizamiento in vitro}

La rizogénesis es un proceso desencadenado por la interacción de múltiples factores dentro de los cuales se menciona un adecuado balance auxinacitoquinina, el tipo y disponibilidad de la fuente de carbono, el tipo y concentración de sales minerales, la intensidad lumínica y la temperatura, así como concentraciones de otros reguladores de crecimiento como el ácido giberélico, que presentan un papel decisivo en la inducción radical (Apraez, Romo y Lagos, 20 I2; Rojas García y Alarcón, 2004).

Respecto a la aplicación de reguladores del crecimiento en la etapa de enraizamiento, un estudio realizado por Levitus, Echenique, Rubinstein, Hopp y Mroginski (2004) demostraron que elevadas dosis de auxinas son contraproducentes, induciendo el desarrollo de callo en la base de los explantes, aumentando el tiempo de generación de raíces o inhibiendo el desarrollo de las mismas, siendo evidente este fenómeno en los tratamientos E3 y E4.

Ensayos realizados por Yaguache (2009) en Solanum cajanumensis (tomate de árbol silvestre), han demostrado la presencia de concentraciones óptimas de auxinas y citoquininas para la formación de raíces. El cuadro 5 muestra que el enraizamiento de los explantes de esta especie, no requiere necesariamente de auxinas u otro regulador de crecimiento exógeno $\left(\mathrm{AG}_{3}\right)$ para el desarrollo y formación de raíces. Lo mencionado se reafirma en el tratamiento $\mathrm{E} 2$, donde se evidenció que el $\mathrm{AG}_{3}$ es un inhibidor del enraizamiento; sin embargo, una adecuada interacción con las concentraciones endógenas de auxinas y citoquininas, permiten la elongación del tallo y el enraizamiento. El callo generado en este ensayo probablemente se debió al exceso de auxina presente en la planta, debido a que el $\mathrm{AG}_{3}$ estimula la síntesis endógena de este regulador del crecimiento (Coleto, 1994).
Con respecto a los tratamientos sin reguladores de crecimiento, el tipo de gelificante presentó un papel importante, mostrando diferencias significativas en la mayoría de las variables evaluadas, siendo los tratamientos E5 y E6 los que revelaron los mejores resultados. En comparación con el trabajo de Correia et al. $(20 \mathrm{l}$ I), se obtuvo un mayor número promedio de raíces por explante, con una mayor longitud y en un menor periodo de tiempo. Lo mencionado se debe probablemente a las diferencias en la composición química de los gelificantes empleados.

El agar es un polisacárido constituido principalmente por galactosas y galactomananos, estos oligosacáridos están relacionados con las vías de traducción de señales de crecimiento y desarrollo; además, se ha demostrado que la forma oxidada de la galactosa (ácido D-galacturónico) es un estimulador del enraizamiento en frutales (Costales, Nápoles y Falcón, 2007; Domoní y Benítez, 2004). Por su parte, el Phytagel® es un gelificante sintético, el cual no interviene en el crecimiento y desarrollo de la planta (Loaiza, 2008).

\section{Conclusiones}

La dosis de 2,5\% de $\mathrm{Ca}\left(\mathrm{ClO}_{2}\right)$ en la etapa de desinfección in vitro produjo una sobrevivencia significativamente mayor comparada con la dosis de 5,0\%.

El mejor tratamiento para la multiplicación in vitro del material fue el medio MI, el cual es un medio MS al 100\% suplementado con I,8 g/L de phytagel $\circledast$, 0,5 mg/L de $A G_{3}, 0,25 \mathrm{mg} / \mathrm{L}$ de BAP y 2,0 $\mathrm{mg} / \mathrm{L}$ de $\mathrm{PaCa}$, el cual mostró el mejor balance entre el número promedio de brotación/explante y el número promedio de entrenudos/explante, sin provocar cantidad excesiva de callo.

La mejor respuesta al enraizamiento in vitro se obtuvo en los medios de cultivo E5 (MS al 100\% suplementado con 6,0 g/L de agary $3 \%$ de sacarosa) y E6 (MS al I00\% suplementado con 8,0 g/L de agar y $3 \%$ de sacarosa), los cuales mostraron los periodos de enraizamiento más cortos, el mayor número promedio de raíces y la mayor longitud promedio de raíz y tallo. 


\section{Agradecimientos}

Los investigadores agradecen a la Vicerrectoría de Investigación y Extensión del Tecnológico de Costa Rica, así como a la Comisión Nacional de Rectores (CONARE) por el financiamiento de esta investigación.

\section{Referencias}

Abdelwahd, R; Hakam, N; Labhilili, M. y UduPA, S. (2008). Use of an adsorbent and antioxidants to reduce the effects of leached phenolics in in vitro plantlet regeneration of faba bean. African Journal of Biotechnology 7: 997- 1002.

Alberts, B; Johnson, A; Lewis, J; Raff, M; Roberts, K. y Walter, P. (2002). Parte I. Introducción a la Célula: Capítulo 3. Proteínas. pp. 170. En Alberts, B; Johnson, A; Lewis, J; Raff, M; Roberts, K; Walter, P. (eds). 2002. Biología Molecular de la Célula. 4 ed. Ediciones Omega, S.A. Barcelona, España.

Apraez, J; Romo, J. y Lagos, T. (2012). Regeneration of tree tomato plants (Cyphomandra betacea Cav. Sendt.) induced by organogenesis from callus. Rev. de Ciencias Agrícolas. 29 (2): | 08- | I5

Calva, G. y Pérez, J. (2005). Cultivo de Células y Tejidos Vegetales: Fuente de alimentos para el futuro. Rev. Digital Universitaria. $6(\mid 1): 1-16$.

Cassells, A.C. y Doyle, B.M. (2005). Pathogen and biological contamination management: the road ahead. pp. 35-50 in Loyola-Vargas V.M. \& Vázquez-Flota F. (eds.). Plant Cell Culture Protocols. Humana Press, New York.

Coleto, J. (1994). Crecimiento y desarrollo de las especies frutales. El sistema radícular. 2da ed. Madrid, España. Editores Mundi-Prensa. 169p.

Correia, S; Lopes, M. y Canhoto, J. (20/2). Somatic embryogenesis in tamarillo (Cyphomandra betacea): approaches to increase efficiency of embryo formation and plant development. Plant Cell Tiss Organ Cult. 109:143- 152.

Correia, S; Lopes, M. y Canhoto, J. (20I I). Somatic embryogenesis induction system for cloning an adult Cyphomandra betacea (Cav.) Sendt. (tamarillo). Trees 25: 1009-1020

Costales, D; Nápoles, M. y Falcón, A. (2007). Influencia de oligosacáridos de quitosana y pectina en la interacción simbiótica soya-Bradyrhizobium. Rev. Cubana de Ciencia Agrícola. 41 (2): |75-|8|.

Den Boer B.G. y Murray, J.A. (2000). Triggering the cell cycle in plants. Trends Cell Biol. I0: 245-250.

Domoní, M. y Benítez, B. (2004). Uso de biopreparados como promotores de enraizamientos en margullos de Ficus (Ficus benjamina). Cultivos Tropicales 25 (3): 45-48.

Espinosa, J; Trillos, O; Hoyos, R; Afanador, L. y Correa, G. (2005). Potencial de propagación in vitro para el tomate de árbol partenocárpico Cyphomandra betacea Cav. (Sendtn). Rev. Nal. Agr. Medellín. 58 (I): 2685- 2695.
George, E. (2008). Plant Tissue Culture Procedure - Background. pp. I-28 in George, E; Hall, MA; De Klerk, G. (eds). 2008. Plant propagation by tissue culture. 3 ed. Springer. Dordrecht, Netherlands.

George, E; Hall, MA. y De Klerk, G. (2008). The Components of Plant Tissue Culture Media I : Macro- and Micro-Nutrients. pp. 65-1I5 in George, E; Hall, MA; De Klerk, G. (eds). 2008. Plant propagation by tissue culture. 3 ed. Springer. Dordrecht, Netherlands.

Levitus, G; Echenique, V; Rubinstein, C; Hopp, E. y Mroginski, L. (2004). Biotecnología y Mejoramiento Vegetal. Métodos de propagación y conservación de germoplasma. Instituto Nacional de Tecnología Agropecuaria. 648p.

Loaiza, C. (2008). Análisis fisiológico del efecto de tres marcas de agar y Gelrite en la germinación y desarrollo in vitro de plántulas de Echinocactus platyacanthus Link et Otto (Cactaceae). Tesis para la obtención del título de Licenciado en Biología. Universidad Autónoma del Estado de Hidalgo. Pachuca, México.

Lobo, M. (200 I).Tomate de árbol (Cyphomandra betacea Sendt), frutal promisorio para la diversificación del agro andino. Programa de Recursos Genéticos y Biotecnología Vegetales CORPOICA C.I. La Selva Rionegro Ant. 27 p.

López, P; Iracheta, L; Castellanos, M; Méndez, I; Aguirre J.F; Gutiérrez, A; Ojeda, M. y Pérez, B. (20II). Variación en la tolerancia a desinfectantes de genotipos élite de Coffea spp. cultivados in vitro. Revista Mexicana de Ciencias Agrícolas, 2 (5): 645-657

Minitab Inc. 20 I0. Minitab (software). Ver. 16.1.0.0.

Moshkov, l; Novikova, G.V; Hall, M.A. y George, E.F. (2008). Plant Growth Regulators III: Gibberellins, Ethylene, Abscisic Acid, their Analogues and Inhibitors; Miscellaneous Compounds. pp. 227-282 in George, E; Hall, MA; De Klerk, G. (eds). 2008. Plant propagation by tissue culture. 3 ed. Springer. Dordrecht, Netherlands.

Pompeu, G, Gratão, P; Vitorello, V. y Azevedo, R. (2008). Antioxidant isoemzyme responses to nickel-induced stress in tabacco cell suspension culture. ScientiaAgricola65: 548552.

Preece, J. (2008). Stock Plant Physiological Factors Affecting Growth and Morphogenesis. pp. 403-422 in George, E; Hall, MA; De Klerk, G. (eds). 2008. Plant propagation by tissue culture. 3 ed. Springer. Dordrecht, Netherlands.

Rojas, S; García J. y Alarcón, M. (2004). Propagación asexual de plantas. Conceptos Básicos y Experiencias con Especies Amazónicas. Ministerio de Agricultura y Desarrollo Rural. CORPOICA. Programa Nacional de Transferencia de Tecnología, Pronatta. Impreso en Colombia.

Tabiyeh, D; Bernard, F; Shacker, H. (2006). Investigation of glutathione, salicylic acid and GA3 effects on browning in Pistacia vera shoot tips culture. Acta Horticulturae. 726: 201-204.

Tang,W; Harris, L; Outhavong,V.y Newton, R. (2004).Antioxidants enhance in vitro plant regeneration by inhibiting the accumu- 
lation of peroxidase in Virginia pine (Pinus virginiana Mill.). Plant Cell Reports 22: 871-877.

Turrens, J. (2003). Mitochondrial formation of reactive oxygen species. Journal of Physiology 552: 335-344.

Valderrama, R; Corpas, F; Carreras, A; Fernández-Ocaña, A; Chaki, M; Luque, F; Gómez-Rodríguez, M; Colmenero-varea, P; Del Río, L. y Barroso, J. (2007). Nitrosative stress in plants. FEBSLetters 581: 453-461.

Van Staden, J; Fennell, C. y Taylor, N. (2006). Plant stress in vitro: Theroleof phytohormones. Acta Horticulturae. 725: 55-62.

Van Staden, J; Zazimalova, E. y George, E. (2008). Plant Growth Regulators II: Cytokinins, their Analogues and Antagonists. pp.205-226 in George, E; Hall, M.A; De Klerk, G. (eds). 2008. Plant propagation by tissue culture. 3 ed. Springer. Dordrecht, Netherlands.

Vatanpour-Azghandi, A; Villiers, T; Ghorbani, A. y Tajabadi, A. (2002). The microscopy of tissue decolouration and browning problem in pistachio callus cultures. Acta Horticulturae. 591: 377-388.

Yaguache, Á. (2009). Germinación, brotación y conservación in vitro de Solanum cajanumensis, Kunth (tomate de árbol silvestre). Tesis de grado previo a la obtención del título de Ingeniero Agropecuario. Universidad Técnica Particular de Loja. Loja, Ecuador. 